\title{
Continuous 7-Month Internet of Things-Based Monitoring of Health Parameters of Pregnant and Postpartum Women: Prospective Observational Feasibility Study
}

Johanna Saarikko $^{1}$, RM, MHSc; Hannakaisa Niela-Vilen ${ }^{1}, \mathrm{RM}, \mathrm{PhD}$; Eeva Ekholm ${ }^{2,3}$, MD, PhD; Lotta Hamari ${ }^{1,4}$, PT, PhD; Iman Azimi ${ }^{5}$, PhD; Pasi Liljeberg ${ }^{5}$, PhD; Amir M Rahmani ${ }^{6}$, MBA, PhD; Eliisa Löyttyniemi ${ }^{7}$, MSc; Anna Axelin ${ }^{1}, \mathrm{RN}, \mathrm{PhD}$

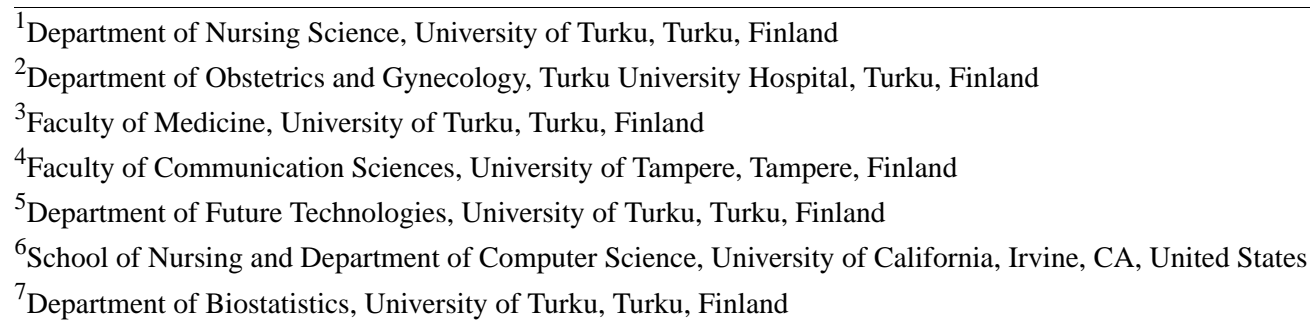

Corresponding Author:

Amir M Rahmani, MBA, PhD

School of Nursing and Department of Computer Science

University of California

106D Berk Hall

Irvine, CA, 92697-3959

United States

Phone: 19498243590

Email: a.rahmani@uci.edu

\begin{abstract}
Background: Monitoring during pregnancy is vital to ensure the mother's and infant's health. Remote continuous monitoring provides health care professionals with significant opportunities to observe health-related parameters in their patients and to detect any pathological signs at an early stage of pregnancy, and may thus partially replace traditional appointments.

Objective: This study aimed to evaluate the feasibility of continuously monitoring the health parameters (physical activity, sleep, and heart rate) of nulliparous women throughout pregnancy and until 1 month postpartum, with a smart wristband and an Internet of Things (IoT)-based monitoring system.

Methods: This prospective observational feasibility study used a convenience sample of 20 nulliparous women from the Hospital District of Southwest Finland. Continuous monitoring of physical activity/step counts, sleep, and heart rate was performed with a smart wristband for 24 hours a day, 7 days a week over 7 months (6 months during pregnancy and 1 month postpartum). The smart wristband was connected to a cloud server. The total number of possible monitoring days during pregnancy weeks 13 to 42 was 203 days and 28 days in the postpartum period.

Results: Valid physical activity data were available for a median of 144 (range 13-188) days (75\% of possible monitoring days), and valid sleep data were available for a median of 137 (range 0-184) days (72\% of possible monitoring days) per participant during pregnancy. During the postpartum period, a median of 15 (range 0-25) days (54\% of possible monitoring days) of valid physical activity data and 16 (range $0-27$ ) days (57\% of possible monitoring days) of valid sleep data were available. Physical activity decreased from the second trimester to the third trimester by a mean of 1793 (95\% CI 1039-2548) steps per day $(P<.001)$. The decrease continued by a mean of 1339 (95\% CI 474-2205) steps to the postpartum period $(P=.004)$. Sleep during pregnancy also decreased from the second trimester to the third trimester by a mean of 20 minutes (95\% CI -0.7 to 42 minutes; $P=.06$ ) and sleep time shortened an additional 1 hour $(95 \%$ CI 39 minutes to 1.5 hours) after delivery $(P<.001)$. The mean resting heart rate increased toward the third trimester and returned to the early pregnancy level during the postpartum period.
\end{abstract}


Conclusions: The smart wristband with IoT technology was a feasible system for collecting representative data on continuous variables of health parameters during pregnancy. Continuous monitoring provides real-time information between scheduled appointments and thus may help target and tailor pregnancy follow-up.

(JMIR Form Res 2020;4(7):e12417) doi: 10.2196/12417

\section{KEYWORDS}

prenatal care; postnatal care; wearable electronics; biosensing; cloud computing; mHealth; physical activity; sleep; heart rate

\section{Introduction}

Monitoring and follow-ups during pregnancy are vital to ensure the health and well-being of pregnant women and their unborn infants. Thus far, monitoring of pregnancy is performed at scheduled appointments by health care professionals in maternity care units [1]. Instead of intermittent measurements tied to time and place, remote and continuous monitoring could provide significant opportunities for health care professionals to observe the health-related parameters of their patients [2] and detect abnormal changes in maternal adaptation to pregnancy and liability to pregnancy complications early. Remote monitoring might support personalized care as maternity care could be tailored according to the received information. A personalized monitoring approach could also enhance a woman's self-management because it makes the woman more aware of her health and might commit her to pregnancy care [3].

The Internet of Things (IoT) provides methods for ubiquitous and continuous maternity monitoring. The IoT is a high-level network of objects (ie, things) that are wirelessly connected to servers to provide efficient and comprehensive services $[4,5]$. In practice, the pregnant woman wears sensors that monitor health-related parameters, enabling her and health care professionals to track the data through web-based user interfaces anywhere and at any time [5]. Recently, the use of various eHealth applications in pregnancy care has sharply increased-for example, for remote monitoring of blood glucose - and the number of maternity care visits for women with gestational diabetes mellitus has decreased with no differences in maternal or neonatal outcomes noted [6,7]. Further, pulse and blood pressure sensors in a smartphone application have been developed, and the feedback from pregnant women has been positive [8,9].

Physical activity and sleep are significant for a pregnant woman's general well-being and quality of life [10]. Physical activity decreases as pregnancy progresses [11], and sleep disorders are common among pregnant women, especially during the third trimester and during the postpartum period [12]. Both physical activity and sleep are usually measured by subjective self-reports [11-13], which is complicated because self-reports may over or underestimate the duration of sleep or activity $[13,14]$. On the other hand, device-based monitoring has the potential to increase physical activity because having visibility to one's daily activity is known to be an incentive to increase physical activity [15]. Although smart wristbands are widely utilized to measure activity, sleep, and heart rate, their use in pregnant women is still scarce [2]. Continuous device-based monitoring would provide unique and representative data on the levels and changes of activity and sleep during pregnancy and the postpartum period. Furthermore, heart rate measures could be utilized to evaluate the intensity of the physical activity of pregnant and postpartum women. Continuous monitoring could also be useful to target interventions to those needing them the most and to measure health outcomes systematically.

This study aimed to evaluate the feasibility of continuous monitoring of health parameters (physical activity, sleep, and heart rate) of nulliparous women throughout pregnancy and until one month postpartum with a smart wristband and an IoT-based monitoring system.

\section{Methods}

\section{Study Design and Settings}

This study was conducted as a prospective observational feasibility study on nulliparous women attending two maternity outpatient clinics in Southern Finland between May 2016 and June 2017. Physical activity, sleep, and heart rate data were collected with a smart wristband integrating a photoplethysmogram bio-sensor to measure heart rate [16] and an inertial measurement unit to track activity and sleep [17]. The study design is presented in Figure 1.

The study was carried out per the Code of Ethics of the World Medical Association (Declaration of Helsinki) and approved by the Joint Ethics Committee of the Hospital District of Southwest Finland (35/1801/2016) and the university hospital. Permission to use Garmin Vivosmart (HR, Garmin) smart wristbands in this study was obtained from the manufacturer. The study was not registered due to the feasibility design. 
Figure 1. The study design.

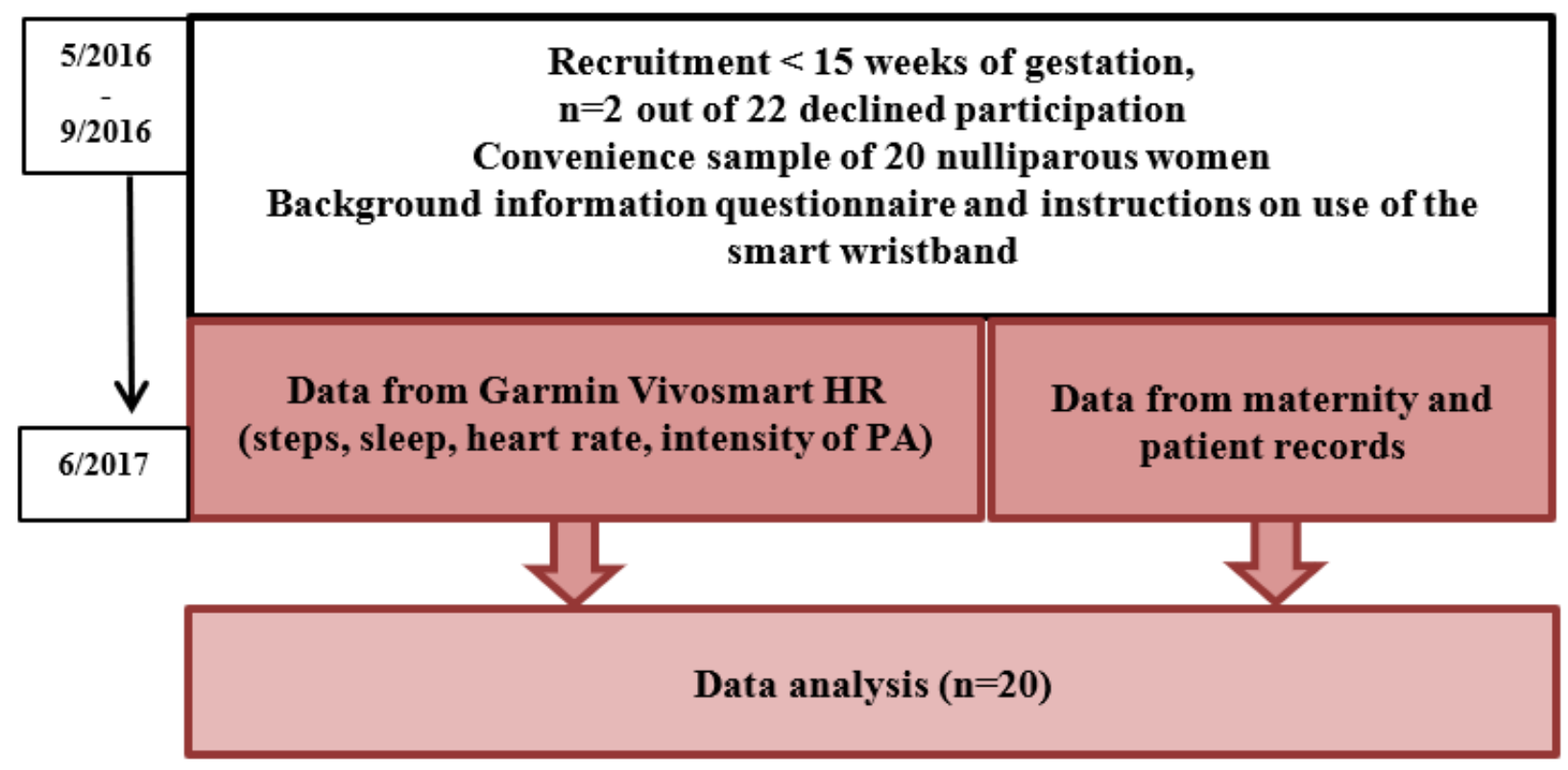

\section{Participants and Recruitment}

In Finland, all pregnant women are offered a screening ultrasound free of charge at the end of their first trimester. A convenience sample of 20 pregnant women was recruited from this visit. Criteria for eligibility were women (1) expecting their first child, (2) $\geq 18$ years of age, and (3) $\leq 15$ of weeks of singleton gestation. Women were excluded if they did not understand Finnish or English or did not have a PC, tablet, or mobile device with which to synchronize data.

The midwives at the maternity outpatient clinics informed the eligible women about the study. After providing oral and written information, the midwives asked permission for the researchers to be in contact with potential participants $(\mathrm{N}=22)$. The researchers explained the study purpose and procedures to the women by telephone and scheduled a meeting if a woman was willing to participate. Two women declined participation because they felt that they would not wear the smart wristband. Written informed consent was obtained from all participants at the meeting with the researchers. In addition, a smart wristband and instructions on how to use it were given to each participant, and background information was obtained through a questionnaire.

\section{Outcome Measures and Data Collection}

Maternal background characteristics of age, BMI, marital status, education, employment status, smoking, and pre-pregnancy physical activity habits were collected with a questionnaire at the meeting with the researcher. Data on pregnancy and delivery were collected from the maternity card and hospital electronic patient records.

Physical activity, sleep, and heart rate data were collected objectively using a Garmin Vivosmart, small $(21 \mathrm{~mm} \times 12.3$ $\mathrm{mm}$ ) and light (29.6 g) smart wristband. The device has shown an acceptable level of validity for step counts tested under laboratory conditions against the Optogait system (OPTOGait,
Microgate Srl) and a manual hand counter on the treadmill $[18,19]$. The device detected sleep automatically based on heart rate and hand movements during regular sleep hours, not during the day. Physical activity intensities were estimated by comparing heart rate data with the data collected by an accelerometer sensor when acceleration was detected, in comparison to the patient's average resting heart rate. If the heart rate sensor was not on, the device calculated the number of steps per minute to evaluate moderate-to-vigorous physical activity (MVPA) minutes. At least 10 consecutive minutes must be recorded to earn intensity minutes so that either step count rate or heart rate was elevated above the predefined moderate-intensity threshold [20]. The women were instructed to wear the activity tracker for 24 hours a day during their pregnancy and for 1 month after delivery, totaling 7 months. They were advised to synchronize the devices once a day or at least when charging the devices every 5 days. Data were accessible for both the researchers and the women.

An IoT-based system was implemented to provide remote health monitoring throughout pregnancy and postpartum. The monitoring system leverages an amalgamation of different sensing, communication, and computing resources to collect, transmit, and analyze data [5,21]. The architecture of this system is illustrated in Figure 2. First, a smart wristband was used to collect health data from the mother remotely. Second, the collected data were transmitted to cloud servers via a gateway device, which was a smartphone or a personal computer. Third, the cloud was responsible for storing the data and for performing the following data preprocessing and analysis methods.

Data collection rates were not fixed throughout monitoring, as the Garmin provided the parameters at different rates. Therefore, we first homogenized the heart rate values by interpolating or averaging them. We then selected a 15-minute interval between successive values. Moreover, step counts were obtained from the Garmin. We leveraged step count values to specify physical activity levels. Sleep duration per night was extracted from the 
sleep data provided by Garmin. To validate this data, we carried out a manual cross-check between the sleep data and other data, including hand movement and heart rate values. The sleep data were corrected or removed in cases of mismatch.

Figure 2. An Internet of Things-based system for remote maternity monitoring.

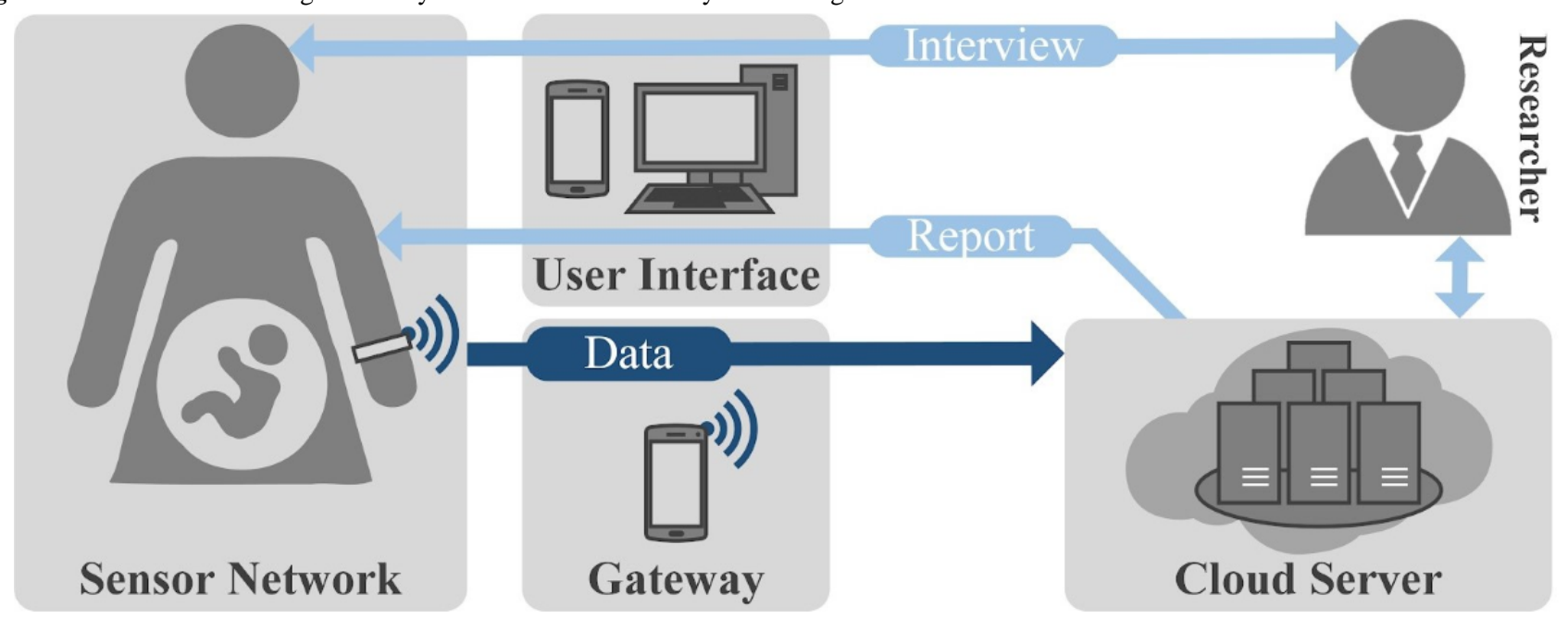

\section{Statistical Data Analysis}

Physical activity (step count) and heart rate data were accepted as valid for analyses if the participant wore the device for at least 10 hours per day while awake [22,23] at least 4 days per week [24]. The only exception was the week of delivery, from which all awake data were included in the analyses because the delivery week is shorter in most cases (if woman deliverers at $40+1$ gestational week, this week includes only 2 days). Sleep measurements were considered successful if there was no off-wrist time during the sleep period [25] and at least 4 sleep periods measured per week. Sleep duration was defined as the number of minutes scored as sleep by the Garmin algorithm.

To describe the women's background information and monitored health parameters (step counts, sleep and awake minutes, heart rate, and MVPA minutes), means, SD, or CI and medians with ranges were used as continuous variables and counts with proportions for categorical variables. Daily step counts, sleep, and heart rate data from 13 weeks of gestation to 1 month postpartum were presented for the second and third trimesters and the postpartum period (averaging all accepted data during each period). The changes in weekly step counts and sleep minutes were assessed throughout pregnancy. These analyses were performed with a linear mixed model with repeated measures, including one within factor (time = gestational weeks). A compound symmetry covariance structure was used for time. This method allows women with missing values to be included in the analyses. The same method was used to study differences in average step count, sleep, and awake minutes between pregnancy trimesters. Changes over trimesters in MVPA minutes were analyzed using the Friedman test because the normality assumption was not met.

Spearman correlation testing was used to explore associations between mean daily step count by the second and third trimesters and the postpartum period as well as mean daily sleep minutes by the trimesters and postpartum period. MVPA minutes were compared to the recommendation for physical activity in healthy pregnant women: 150 minutes of moderate-intensity or 75 minutes of vigorous-intensity activity per week [26]. All tests were performed as two-sided tests with a significance level set at .05 . The analyses were performed using SAS System, version 9.4 for Windows (SAS Institute).

\section{Results}

\section{Participants}

A total of 20 of 22 eligible pregnant women (refusal rate of 9\%) were enrolled in the study. The mean gestational age at recruitment was 12 (SD 2) weeks of gestation. The background characteristics of the women are described in Table 1 and the perinatal outcomes are described in Table 2. 
Table 1. Descriptive statistics for maternal background characteristics $(\mathrm{N}=20)$.

\begin{tabular}{|c|c|}
\hline Characteristic & Participants \\
\hline Age (years), mean (SD) & $26(5.0)$ \\
\hline Gestational age at recruitment (week), mean (SD) & $12(2.1)$ \\
\hline \multicolumn{2}{|l|}{ Highest educational qualification, n (\%) } \\
\hline Primary education & $4(20)$ \\
\hline Secondary education & $9(45)$ \\
\hline College or university of applied sciences & $4(20)$ \\
\hline University & $3(15)$ \\
\hline \multicolumn{2}{|l|}{ Marital status, n (\%) } \\
\hline Married or living with a partner & $17(85)$ \\
\hline Single & $3(15)$ \\
\hline \multicolumn{2}{|l|}{ Employment status, n (\%) } \\
\hline Working & $13(65)$ \\
\hline Unemployed & $2(10)$ \\
\hline Student & $5(25)$ \\
\hline Pre-pregnancy BMI $\left(\mathrm{kg} / \mathrm{m}^{2}\right)$, median (range) & $24.4(17.7-43.5)$ \\
\hline Pre-pregnancy smoking, n (\%) & $7(35)$ \\
\hline Smoking during pregnancy, $\mathrm{n}(\%)$ & $5(25)$ \\
\hline Pre-pregnancy physical activity (almost daily), n (\%) & $12(60)$ \\
\hline
\end{tabular}

Table 2. Descriptive statistics for perinatal outcomes $(\mathrm{N}=20)$.

\begin{tabular}{ll}
\hline Perinatal outcomes & Participants \\
\hline $\begin{array}{l}\text { Gestational age at delivery (week), mean (SD) } \\
\text { Gestational diabetes, n (\%) }\end{array}$ & $39.4(2.6)$ \\
Means of delivery, n (\%) & $5(25)$ \\
$\quad$ Vaginal & $14(70)$ \\
$\quad$ Vacuum-assisted & $4(20)$ \\
$\quad$ Emergency cesarean section & $2(10)$ \\
Birth weight (g), median (range) & $3415(1100-4445)$
\end{tabular}

\section{Physical Activity and Sleep}

The recordings yielded valid physical activity data for a median of 144 (range 13-188) days, which represented 75\% of the 6-month data collection period during pregnancy. During the postpartum period, valid data were available for a median of 15 (range $0-25$ ) days, representing $54 \%$ of the 1-month data collection period.

Physical activity decreased from the second trimester to the postpartum period (Figure 3 ). The mean daily steps during the second trimester were 6838 (95\% CI 5866-7810) and decreased by a mean of 1793 (95\% CI 1039-2548) steps per day in the third trimester $(P<.001)$. The daily steps further decreased by a mean of 1339 (95\% CI 474-2205) steps in the postpartum period $(P=.004)$. In weekly comparisons, the average daily step count was between 6000 and 7000 from 13-31 gestational weeks. After gestational week 32, the mean daily step count decreased to 5000 by 36 gestational weeks and further to approximately 4000 steps/day after that. The most significant decrease in physical activity occurred at 32 gestational weeks ( $P<.05$ in most weekly comparisons) (Table 3 ).

Valid sleep data were available from a median of 137 days (range $0-184$ ), representing $72 \%$ of data during pregnancy. During the postpartum period, a median of 16 days (range 0-27) of valid data (57\%) was used in the analyses (Table 3). Sleep minutes decreased, and nightly awake minutes increased from the second trimester to the postpartum period (Figure 3). The participants slept a mean of 8 hours (95\% CI 7.6-8.3 hours) during the second trimester and a mean of 20 minutes $(95 \% \mathrm{CI}$ -0.7 to 42 minutes) less per night in the third trimester $(P=.06)$. The total night sleep time shortened an additional 1 hour $(95 \%$ CI 39 minutes to 1.5 hours) in the postpartum period $(P<.001)$. In weekly comparisons, the average daily sleep minutes were between 450 and 500 from 13 to 38 gestational weeks. After 
gestational week 38, the mean daily sleep minutes decreased to $435(P<.05$ in most weekly comparisons; Table 3).

Figure 3. Mean and standard deviation of the sleep data and step counts per day by week during pregnancy and postpartum ( $\mathrm{n}=2-19)$.
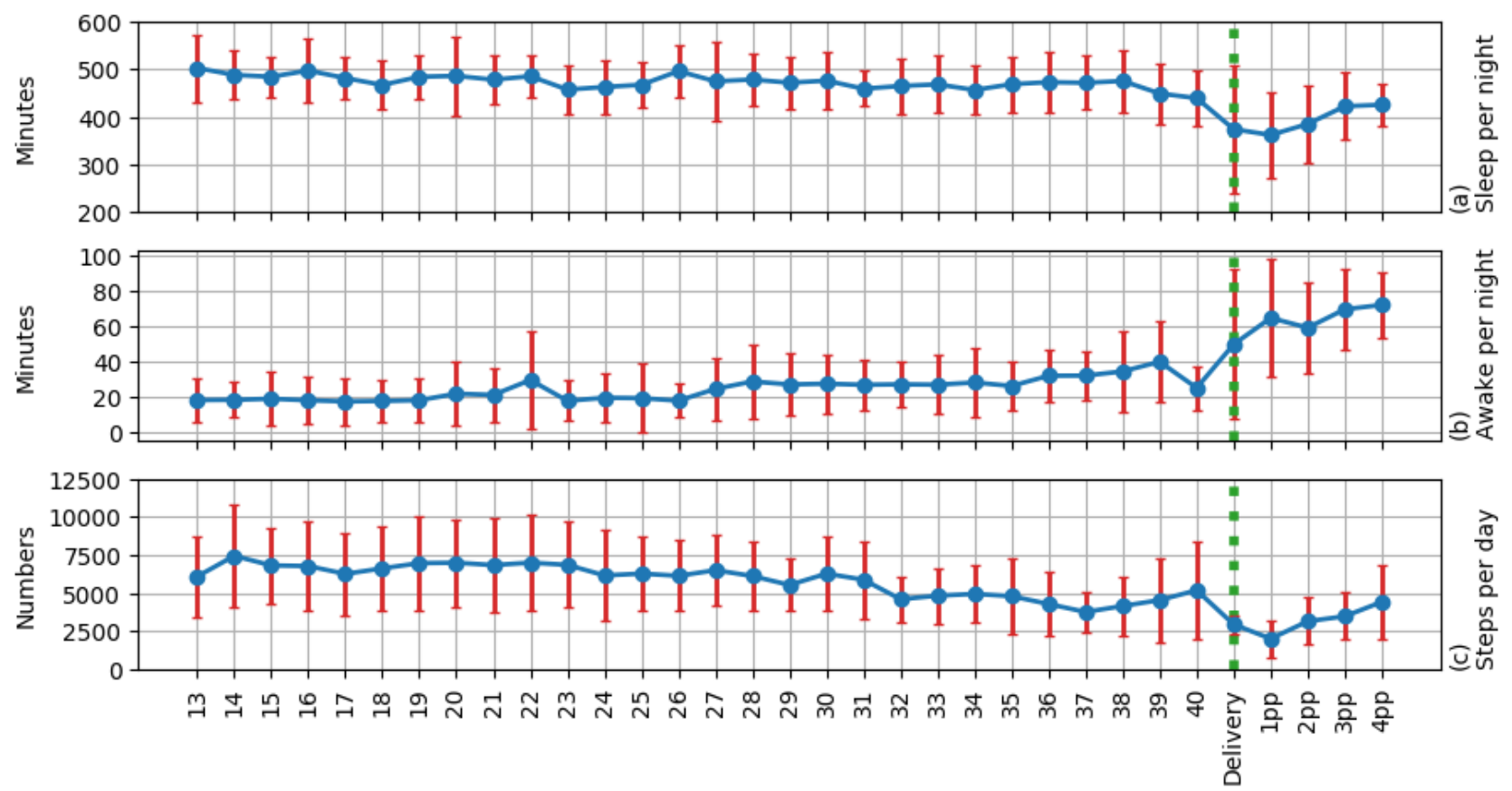

Pregnancy and postpartum weeks

Table 3. Mean step counts and sleep minutes by trimesters and the postpartum period.

\begin{tabular}{|c|c|c|c|c|}
\hline Variables & $\begin{array}{l}\text { Second trimester } \\
(\mathrm{n}=19)\end{array}$ & $\begin{array}{l}\text { Third trimester } \\
(\mathrm{n}=17)\end{array}$ & $\begin{array}{l}\text { Postpartum period } \\
(\mathrm{n}=12)\end{array}$ & $\begin{array}{l}\text { Overall differences be- } \\
\text { tween periods ( } P \text { value })\end{array}$ \\
\hline Valid physical activity days, $\mathrm{n}\left(\%^{\mathrm{a}}\right)$ & $76(70)$ & $51(67)$ & $12(42)$ & \\
\hline \multicolumn{5}{|l|}{ Steps per day ${ }^{b}$} \\
\hline Mean $(\mathrm{CI})$ & $6838(5866-7810)$ & $5045(4049-6041)$ & $3705(2635-4776)$ & $<.001$ \\
\hline Pairwise differences between periods ( $P$ value) & $<.001^{\mathrm{c}}$ & $.004^{\mathrm{d}}$ & $<.001^{\mathrm{e}}$ & \\
\hline Valid sleep days, $\mathrm{n}\left(\%^{\mathrm{a}}\right)$ & $69(63)$ & $48(63)$ & $12(41)$ & \\
\hline \multicolumn{5}{|l|}{ Sleep (min/night) ${ }^{b}$} \\
\hline Mean (CI) & $477(433-501)$ & $457(433-481)$ & $393(367-420)$ & $<.001$ \\
\hline Pairwise differences between periods ( $P$ value) & $.06^{\mathrm{c}}$ & $<.001^{\mathrm{d}}$ & $<.001^{\mathrm{e}}$ & \\
\hline \multicolumn{5}{|l|}{ Awake (min/night) ${ }^{b}$} \\
\hline Mean (CI) & $21(15-27)$ & $32(25-40)$ & $67(52-81)$ & $<.001$ \\
\hline Pairwise differences between periods ( $P$ value) & $.02^{\mathrm{c}}$ & $<.001^{\mathrm{d}}$ & $<.001^{\mathrm{e}}$ & \\
\hline
\end{tabular}

${ }^{\mathrm{a} C a l c u l a t e d ~ d a y s ~ d u r i n g ~ t h e ~ f o l l o w-u p ~ p e r i o d . ~}$

${ }^{\mathrm{b}}$ Measured by Garmin Vivosmart.

${ }^{\mathrm{c}} \mathrm{Second}$ trimester versus third trimester.

${ }^{\mathrm{d}}$ Third trimester versus postpartum period.

${ }^{\mathrm{e}} \mathrm{Second}$ trimester versus postpartum period.

\section{Heart Rate and the Intensity of Physical Activity}

The resting heart rate increased progressively by $17 \%$ from 60 bpm (SD 5) at 13 gestational weeks to $70 \mathrm{bpm}$ (SD 8) at 32 gestational weeks and remained at that level until delivery. The resting heart rate decreased to the early pregnancy level by 4 weeks postpartum (Figure 4).

The intensity of physical activity decreased from the second trimester to the postpartum period. A median of weekly MVPA minutes during the second trimester was 46 (range 0-288) and 
decreased by a mean of 14 minutes (95\% CI -3 to 32 minutes) per week in the third trimester. After delivery, the MVPA minutes further decreased to a median of 15 (range 0-188) minutes per week, but the change was not significant $(P=.08$; Figure 4). Comparing the MVPA minutes with the general recommendation of physical activity for pregnant women, only $47 \%, 24 \%$, and $25 \%$ of the participants achieved the recommended activity level in at least 1 week in the second and third trimesters and the postpartum period, respectively (Table 4).

Figure 4. Resting heart rate values and moderate-to-vigorous physical activity minutes per week during pregnancy and postpartum (n=3-19). HR: heart rate; MVPA: moderate-to-vigorous physical activity.
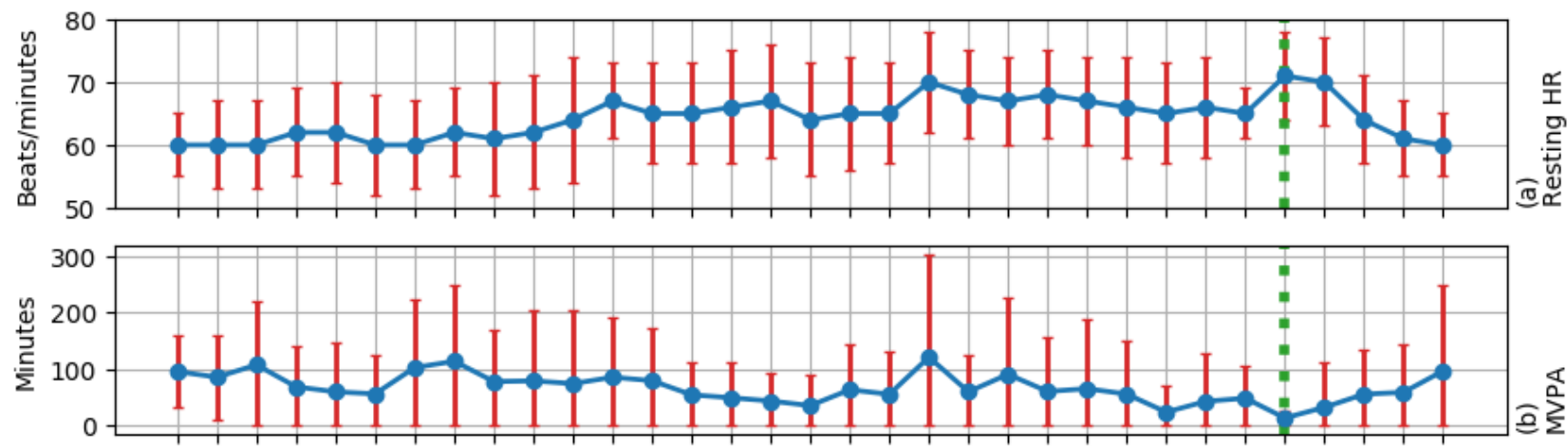

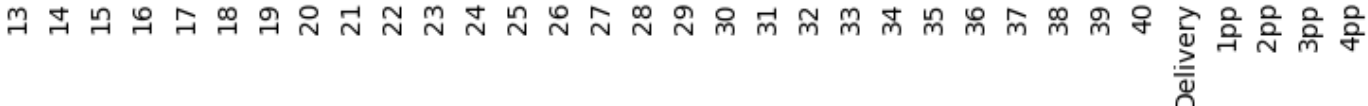

Pregnancy and postpartum weeks

Table 4. Median MVPA minutes by trimester and the postpartum period.

\begin{tabular}{lllll}
\hline Variables & $\begin{array}{l}\text { Second trimester } \\
(\mathrm{n}=19)\end{array}$ & $\begin{array}{l}\text { Third trimester } \\
(\mathrm{n}=17)\end{array}$ & $\begin{array}{l}\text { Postpartum period } \\
(\mathrm{n}=12)\end{array}$ & $\begin{array}{l}\text { Overall difference be- } \\
\text { tween periods }(P \text { value })\end{array}$ \\
\hline MVPA $^{\mathrm{a}}(\mathrm{min} / \text { week) })^{\mathrm{b}}$, median (range) & $46(0-288)$ & $27(0-279)$ & $15(0-188)$ & .08 \\
Participants meeting the recommended $\mathrm{MVPA}^{\mathrm{c}}, \mathrm{n} / \mathrm{N}(\%)$ & $9 / 19(47)$ & $4 / 17(24)$ & $3 / 12(25)$ & $\mathrm{N} / \mathrm{A}^{\mathrm{d}}$ \\
Weeks of 150 MVPA minutes, $\mathrm{n} / \mathrm{N}^{\mathrm{e}}\left(\%^{\mathrm{c}}\right)$ & $43 / 239(18)$ & $19 / 154(12)$ & $7 / 40(18)$ & $\mathrm{N} / \mathrm{A}$ \\
\hline
\end{tabular}

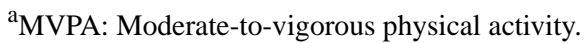

${ }^{\mathrm{b}}$ Measured by Garmin Vivosmart.

${ }^{\mathrm{c}}$ Moderate-to-vigorous physical activity at least in 1 week during follow-up.

${ }^{\mathrm{d}} \mathrm{N} / \mathrm{A}$ : not applicable

${ }^{\mathrm{e}}$ Calculated weeks during the follow-up period.

\section{Discussion}

\section{Principal Findings}

To our knowledge, this is the first continuous, long-term follow-up study measuring physical activity, sleep, and HR during pregnancy and the postpartum period. The results of this study confirmed that this IoT-based system was feasible to monitor health parameters during pregnancy when we collected a large amount of valid physical activity $(75 \%$ of the data collection period) and sleep (72\%) data. After delivery, the amount of data obtained was not representative. Overall physical activity, measured objectively with step counts, was low during pregnancy and postpartum. Sleep time decreased during pregnancy and after delivery, and heart rate increased due to hemodynamic changes. These expected results support the preliminary reliability of a smart wristband with IoT-technology. However, more research is needed to validate the continuous monitoring of pregnant and postpartum women.

\section{Evaluation of the Health Parameters: Physical Activity, Sleep, and Heart Rate}

Physical activity (daily steps) decreased during pregnancy and were quite low in the third trimester and especially during the first month after the delivery. Previous studies using intermittent and subjective measurements also showed that physical activity decreases as the pregnancy progresses $[27,28]$, and one previous study using continuous monitoring also found that step counts decrease in inactive pregnant women as pregnancy proceeded [29]. According to a previous review [15], the smart wristband itself might increase participant physical activity. However, the effects of physical activity interventions are often short term. Thus we estimated that this was not relevant in our study due to the long follow-up period. After the delivery, it was not expected that the women's physical activity would have returned to the early pregnancy level during the first month. In addition to the recovery from delivery, the transition to first-time parenthood takes time. A smart wristband could be used to illustrate the level of physical activity to a pregnant woman 
herself and, by implication, support her in changing her lifestyle to a more active one. Furthermore, physical activity improves sleep quality during the postpartum period [12,30], and well-rested women are most likely to be physically active; thus, both elements of health should be equally supported.

Our study confirmed previous findings on declining sleep quality and more frequent nocturnal awakenings. In line with the previous study [31], we found sleep quality decline starting from the first trimester. In addition, both the number and duration of nocturnal awakenings seemed to increase as pregnancy proceeded [30] and in the postpartum period [12]. However, the sleep time remained rather high throughout pregnancy and after delivery. Pregnant women's abnormal sleep duration is associated with several maternal problems, such as hypertensive disorders [32], increased body mass index after delivery [33], and depression and anxiety [34]. Moreover, extreme sleep duration during pregnancy has been associated with gestational diabetes [35]. Although the sleep duration of the study participants was mostly sufficient according to the present recommendations, the awake minutes during sleep periods increased during pregnancy. The nocturnal awake minutes reduced sleep quality and probably compromised sleep efficiency. The data on sleep quality in pregnancy are limited; thus, the present study adds significantly to the present knowledge of this subject. Smart wristbands provide many opportunities to measure and support the sleep hygiene of pregnant women in maternity care.

The resting heart rate increased until 32 gestational weeks, a normal hemodynamic change during singleton pregnancy [36]; thus, it appears that a smart wristband is an appropriate tool for measuring heart rate during pregnancy. In the future, heart rate and heart-rate variability could be utilized to study the level of stress or the recovery from physical or mental exertions. Maternal stress is associated with some pregnancy complications [37], and identifying the increase in stress could help with finding suitable interventions to support the pregnant woman. The intensity of the physical activity levels in this study was low, as expected, and decreased considerably during the last month of pregnancy. A comparison with the global physical activity recommendation for pregnant women showed that over half of the participants did not reach the recommended 150 minutes of moderate or vigorous physical activity per week during the second or third trimester.

\section{Limitations}

The study includes distinct limitations due to the feasibility design. The participants were recruited as a convenience sample; however, the sample consisted of a diverse group of primiparous women. Due to the small sample size, the results from this study may not be generalizable. Furthermore, the small sample size did not allow us to perform statistical analyses between outcome predictors and maternal background characteristics or perinatal outcome variables. Although Garmin Vivosmart has been shown to provide a valid measure of step count $[18,19]$ and total sleep time compared with a sleep diary in a healthy adult population [38], it is notable that the device has not been validated in pregnant women. A sleep diary would have strengthened our results. However, due to the extended data collection period, we made the decision not to use such a method. The intensity of physical activity was estimated based on heart rate elevation. This approach is not unambiguous in pregnant women, because even if the resting heart rate increases, the maximal heart rate decreases during pregnancy, resulting in a smaller heart rate reserve.

Furthermore, the specificity of intensity measures is only moderate as the device may underestimate the intensity at higher rates [19]. Therefore, moderate and vigorous activity minutes may be biased. Missing data due to the participants not wearing the smart wristband or not remembering to synchronize the device might have affected our results. The data collection period was, however, very long, and only valid weeks were included in the analysis. The data during pregnancy were representative and covered the long follow-up period well. After delivery, however, other methods for monitoring should be considered. In addition, the smart wristband used in this study was found to be a feasible tool for continuous monitoring during pregnancy [39].

\section{Conclusions}

The smart wristband with the IoT solution seems to be a feasible system to collect representative data on continuous variables such as physical activity, sleep, and heart rate throughout pregnancy. However, more research is needed, and other methods for monitoring after delivery should be considered. Continuous monitoring provides personalized information and thus may help target and tailor pregnancy follow-up. Remote monitoring provides vast opportunities to observe health-related parameters in pregnancy and thus detect pathological signs at an early stage and partly replace traditional appointments. Future studies on predicting complications or support of women with high-risk pregnancies are needed.

\section{Acknowledgments}

This research was supported by the University Foundation (Award 5-863) and Academy of Finland (Awards 313448, 313449, 316810, and 316811). The authors would like to thank the personnel of the maternity clinics for their assistance in data collection. Special thanks to the women who participated in the study.

\section{Authors' Contributions}

JS drafted the manuscript and contributed to the design of the study and the acquisition of data from the participants. JS also analyzed and interpreted the data from the questionnaires and the participant data related to background information and health records. HNV contributed to the design of the study and the acquisition of data from the participants. HNV was also a major 
contributor to drafting the manuscript and revising it critically. EE contributed to the design of the study and revised the manuscript critically throughout the process. LH contributed to drafting the manuscript and analyzed and interpreted the data associated with physical activity, sleep, and heart rate. IA, AR, and PL contributed to the design of the study, facilitated the cloud service for the data collection, and analyzed and interpreted the data from the smart wristbands. EL was responsible for the overall biostatistical data analysis and interpretation. AA was a major contributor to the design of the study, data analysis, and interpretation. AA also contributed to drafting the manuscript and to revising it critically throughout the process. All authors read and approved the final manuscript.

\section{Conflicts of Interest}

None declared.

\section{References}

1. Klemetti R; Hakulinen-Viitanen T. Äitiysneuvolaopas. 2013. URL: http://urn.fi/URN:ISBN:978-952-245-972-5 [accessed 2020-06-25]

2. Phillips SM, Cadmus-Bertram L, Rosenberg D, Buman MP, Lynch BM. Wearable Technology and Physical Activity in Chronic Disease: Opportunities and Challenges. Am J Prev Med 2018 Jan;54(1):144-150. [doi: 10.1016/j.amepre.2017.08.015] [Medline: 29122356]

3. Fantinelli S, Marchetti D, Verrocchio MC, Franzago M, Fulcheri M, Vitacolonna E. Assessment of Psychological Dimensions in Telemedicine Care for Gestational Diabetes Mellitus: A Systematic Review of Qualitative and Quantitative Studies. Front Psychol 2019;10:153 [FREE Full text] [doi: 10.3389/fpsyg.2019.00153] [Medline: 30804842]

4. Sugawara E, Nikaido H. Properties of AdeABC and AdeIJK efflux systems of Acinetobacter baumannii compared with those of the AcrAB-TolC system of Escherichia coli. Antimicrob Agents Chemother 2014 Dec;58(12):7250-7257 [FREE Full text] [doi: 10.1128/AAC.03728-14] [Medline: 25246403]

5. Mieronkoski R, Azimi I, Rahmani AM, Aantaa R, Terävä V, Liljeberg P, et al. The Internet of Things for basic nursing care-A scoping review. Int J Nurs Stud 2017 Apr;69:78-90. [doi: 10.1016/j.ijnurstu.2017.01.009] [Medline: 28189116]

6. van den Heuvel JF, Groenhof TK, Veerbeek JH, van Solinge WW, Lely AT, Franx A, et al. eHealth as the Next-Generation Perinatal Care: An Overview of the Literature. J Med Internet Res 2018 Jun 05;20(6):e202 [FREE Full text] [doi: 10.2196/jmir.9262] [Medline: 29871855]

7. Ming W, Mackillop LH, Farmer AJ, Loerup L, Bartlett K, Levy JC, et al. Telemedicine Technologies for Diabetes in Pregnancy: A Systematic Review and Meta-Analysis. J Med Internet Res 2016 Nov 09;18(11):e290 [FREE Full text] [doi: 10.2196/jmir.6556] [Medline: 27829574]

8. Li KHC, White FA, Tipoe T, Liu T, Wong MC, Jesuthasan A, et al. The Current State of Mobile Phone Apps for Monitoring Heart Rate, Heart Rate Variability, and Atrial Fibrillation: Narrative Review. JMIR Mhealth Uhealth 2019 Feb 15;7(2):e11606 [FREE Full text] [doi: 10.2196/11606] [Medline: 30767904]

9. Runkle J, Sugg M, Boase D, Galvin SL, C Coulson C. Use of wearable sensors for pregnancy health and environmental monitoring: Descriptive findings from the perspective of patients and providers. Digit Health 2019;5:2055207619828220 [FREE Full text] [doi: 10.1177/2055207619828220] [Medline: 30792878]

10. Kolu P, Raitanen J, Luoto R. Physical activity and health-related quality of life during pregnancy: a secondary analysis of a cluster-randomised trial. Matern Child Health J 2014 Nov;18(9):2098-2105. [doi: 10.1007/s 10995-014-1457-4] [Medline: $\underline{24585400]}$

11. Coll CDVN, Domingues MR, Hallal PC, da Silva ICM, Bassani DG, Matijasevich A, et al. Changes in leisure-time physical activity among Brazilian pregnant women: comparison between two birth cohort studies (2004 - 2015). BMC Public Health 2017 Dec 25;17(1):119 [FREE Full text] [doi: 10.1186/s12889-017-4036-y] [Medline: 28122524]

12. Bei B, Coo S, Trinder J. Sleep and Mood During Pregnancy and the Postpartum Period. Sleep Med Clin 2015 Mar;10(1):25-33. [doi: 10.1016/j.jsmc.2014.11.011] [Medline: 26055670]

13. Petrov Fieril K, Glantz A, Fagevik Olsen M. The efficacy of moderate-to-vigorous resistance exercise during pregnancy: a randomized controlled trial. Acta Obstet Gynecol Scand 2015 Jan;94(1):35-42. [doi: 10.1111/aogs.12525] [Medline: 25287282]

14. Bonn SE, Bergman P, Trolle Lagerros Y, Sjölander A, Bälter K. A Validation Study of the Web-Based Physical Activity Questionnaire Active-Q Against the GENEA Accelerometer. JMIR Res Protoc 2015 Jul 16;4(3):e86 [FREE Full text] [doi: 10.2196/resprot.3896] [Medline: 26183896]

15. Brickwood K, Watson G, O'Brien J, Williams AD. Consumer-Based Wearable Activity Trackers Increase Physical Activity Participation: Systematic Review and Meta-Analysis. JMIR Mhealth Uhealth 2019 Apr 12;7(4):e11819 [FREE Full text] [doi: 10.2196/11819] [Medline: 30977740]

16. Allen J. Photoplethysmography and its application in clinical physiological measurement. Physiol Meas 2007 Mar;28(3):R1-39. [doi: 10.1088/0967-3334/28/3/R01] [Medline: 17322588]

17. Snyder JC, Rochelle LK, Marion S, Lyerly HK, Barak LS, Caron MG. Lgr4 and Lgr5 drive the formation of long actin-rich cytoneme-like membrane protrusions. J Cell Sci 2015 Mar 15;128(6):1230-1240 [FREE Full text] [doi: 10.1242/jcs.166322] [Medline: 25653388] 
18. Wahl Y, Düking P, Droszez A, Wahl P, Mester J. Criterion-Validity of Commercially Available Physical Activity Tracker to Estimate Step Count, Covered Distance and Energy Expenditure during Sports Conditions. Front Physiol 2017;8:725 [FREE Full text] [doi: 10.3389/fphys.2017.00725] [Medline: 29018355]

19. Kooiman TJM, Dontje ML, Sprenger SR, Krijnen WP, van DSCP, de GM. Reliability and validity of ten consumer activity trackers. BMC Sports Sci Med Rehabil 2015;7:24 [FREE Full text] [doi: 10.1186/s13102-015-0018-5] [Medline: 26464801]

20. Garmin Vívosmart HR/HR+ Owner's Manual. 2015. URL: https://static.garmin.com/pumac/vivosmart HR OM EN.pdf [accessed 2020-06-25]

21. Al-Fuqaha A, Guizani M, Mohammadi M, Aledhari M, Ayyash M. Internet of Things: A Survey on Enabling Technologies, Protocols, and Applications. IEEE Commun. Surv. Tutorials 2015;17(4):2347-2376. [doi: 10.1109/comst.2015.2444095]

22. McCarthy M, Grey M. Motion Sensor Use for Physical Activity Data: Methodological Considerations. Nurs Res 2015;64(4):320-327 [FREE Full text] [doi: 10.1097/NNR.0000000000000098] [Medline: 26126065]

23. Matthews CE, Hagströmer M, Pober DM, Bowles HR. Best practices for using physical activity monitors in population-based research. Med Sci Sports Exerc 2012 Jan;44(1 Suppl 1):S68-S76 [FREE Full text] [doi: 10.1249/MSS.0b013e3182399e5b] [Medline: 22157777]

24. Khan T, Macaulay S, Norris SA, Micklesfield LK, Watson ED. Physical activity and the risk for gestational diabetes mellitus amongst pregnant women living in Soweto: a study protocol. BMC Womens Health 2016 Dec 18;16(1):66 [FREE Full text] [doi: 10.1186/s12905-016-0345-z] [Medline: 27756289]

25. Reid KJ, Facco FL, Grobman WA, Parker CB, Herbas M, Hunter S, et al. Sleep During Pregnancy: The nuMoM2b Pregnancy and Sleep Duration and Continuity Study. Sleep 2017 May 01;40(5) [FREE Full text] [doi: 10.1093/sleep/zsx045] [Medline: 28369543]

26. American College of Obstetricians Gynecologists' Committee on Obstetric Practice, Breastfeeding Expert Work Group. Committee Opinion No. 658: Optimizing Support for Breastfeeding as Part of Obstetric Practice. Obstet Gynecol 2016 Feb;127(2):e86-e92. [doi: 10.1097/AOG.0000000000001318] [Medline: 26942393]

27. Hayes L, McParlin C, Kinnunen TI, Poston L, Robson SC, Bell R, UPBEAT Consortium. Change in level of physical activity during pregnancy in obese women: findings from the UPBEAT pilot trial. BMC Pregnancy Childbirth 2015 Mar 01;15:52 [FREE Full text] [doi: 10.1186/s12884-015-0479-2] [Medline: 25886590]

28. Nascimento SL, Surita FG, Godoy AC, Kasawara KT, Morais SS. Physical Activity Patterns and Factors Related to Exercise during Pregnancy: A Cross Sectional Study. PLoS One 2015;10(6):e0128953 [FREE Full text] [doi:

10.1371/journal.pone.0128953] [Medline: 26083416]

29. Huberty JL, Buman MP, Leiferman JA, Bushar J, Adams MA. Trajectories of objectively-measured physical activity and sedentary time over the course of pregnancy in women self-identified as inactive. Prev Med Rep 2016 Jun;3:353-360 [FREE Full text] [doi: 10.1016/j.pmedr.2016.04.004] [Medline: 27419036]

30. Mindell JA, Cook RA, Nikolovski J. Sleep patterns and sleep disturbances across pregnancy. Sleep Med 2015 Apr;16(4):483-488. [doi: 10.1016/j.sleep.2014.12.006] [Medline: 25666847]

31. Wilson DL, Barnes M, Ellett L, Permezel M, Jackson M, Crowe SF. Decreased sleep efficiency, increased wake after sleep onset and increased cortical arousals in late pregnancy. Aust N Z J Obstet Gynaecol 2011 Feb;51(1):38-46. [doi: 10.1111/j.1479-828X.2010.01252.x] [Medline: 21299507]

32. Williams MA, Miller RS, Qiu C, Cripe SM, Gelaye B, Enquobahrie D. Associations of early pregnancy sleep duration with trimester-specific blood pressures and hypertensive disorders in pregnancy. Sleep 2010 Oct;33(10):1363-1371 [FREE Full text] [Medline: 21061859]

33. Rognmo K, Sivertsen B, Eberhard-Gran M. Self-reported short sleep duration and insomnia symptoms as predictors of post-pregnancy weight change: Results from a cohort study. Womens Health (Lond) 2016 Dec;12(5):465-474 [FREE Full text] [doi: 10.1177/1745505716668871] [Medline: 27634975]

34. Yu Y, Li M, Pu L, Wang S, Wu J, Ruan L, et al. Sleep was associated with depression and anxiety status during pregnancy: a prospective longitudinal study. Arch Womens Ment Health 2017 Dec;20(5):695-701. [doi: 10.1007/s00737-017-0754-5] [Medline: 28685391]

35. Xu Y, Shi L, Bao Y, Chen S, Shi J, Zhang R, et al. Association between sleep duration during pregnancy and gestational diabetes mellitus: a meta-analysis. Sleep Med 2018 Dec;52:67-74. [doi: 10.1016/j.sleep.2018.07.021] [Medline: 30286382]

36. Hunter S, Robson SC. Adaptation of the maternal heart in pregnancy. Br Heart J 1992 Dec;68(6):540-543 [FREE Full text] [doi: 10.1136/hrt.68.12.540] [Medline: 1467047$]$

37. Coussons-Read ME. Effects of prenatal stress on pregnancy and human development: mechanisms and pathways. Obstet Med 2013 Jun;6(2):52-57 [FREE Full text] [doi: 10.1177/1753495X12473751] [Medline: 27757157]

38. Lee J, Byun W, Keill A, Dinkel D, Seo Y. Comparison of Wearable Trackers' Ability to Estimate Sleep. Int J Environ Res Public Health 2018 Dec 15;15(6) [FREE Full text] [doi: 10.3390/ijerph15061265] [Medline: 29914050]

39. Grym K, Niela-Vilén H, Ekholm E, Hamari L, Azimi I, Rahmani A, et al. Feasibility of smart wristbands for continuous monitoring during pregnancy and one month after birth. BMC Pregnancy Childbirth 2019 Jan 17;19(1):34 [FREE Full text] [doi: 10.1186/s12884-019-2187-9] [Medline: $\underline{30654747]}$ 


\section{Abbreviations}

GDM: gestational diabetes mellitus

IoT: Internet of Things

MVPA: moderate-to-vigorous physical activity

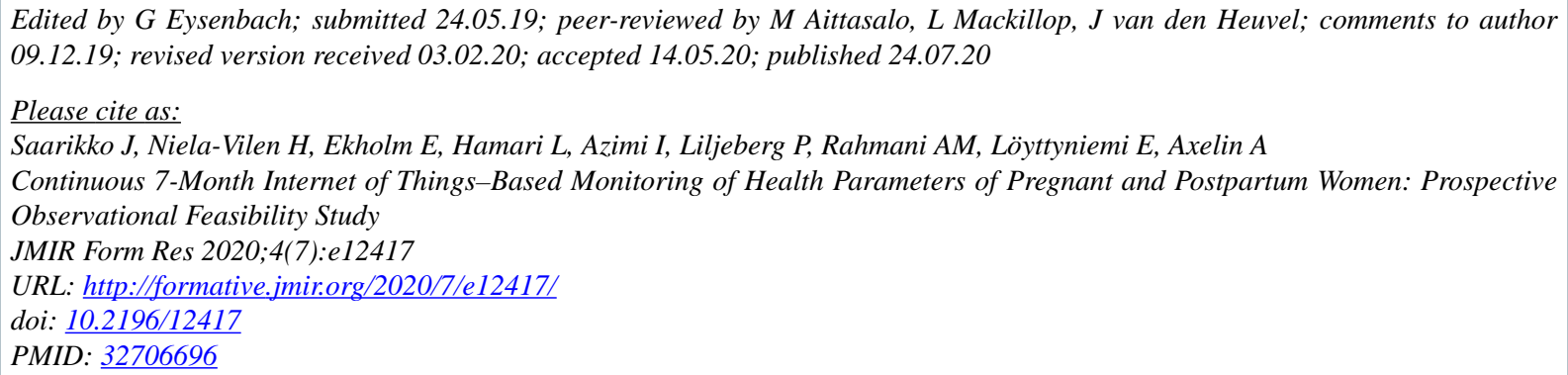

(CJohanna Saarikko, Hannakaisa Niela-Vilen, Eeva Ekholm, Lotta Hamari, Iman Azimi, Pasi Liljeberg, Amir M Rahmani, Eliisa Löyttyniemi, Anna Axelin. Originally published in JMIR Formative Research (http://formative.jmir.org), 24.07.2020. This is an open-access article distributed under the terms of the Creative Commons Attribution License (https://creativecommons.org/licenses/by/4.0/), which permits unrestricted use, distribution, and reproduction in any medium, provided the original work, first published in JMIR Formative Research, is properly cited. The complete bibliographic information, a link to the original publication on http://formative.jmir.org, as well as this copyright and license information must be included. 